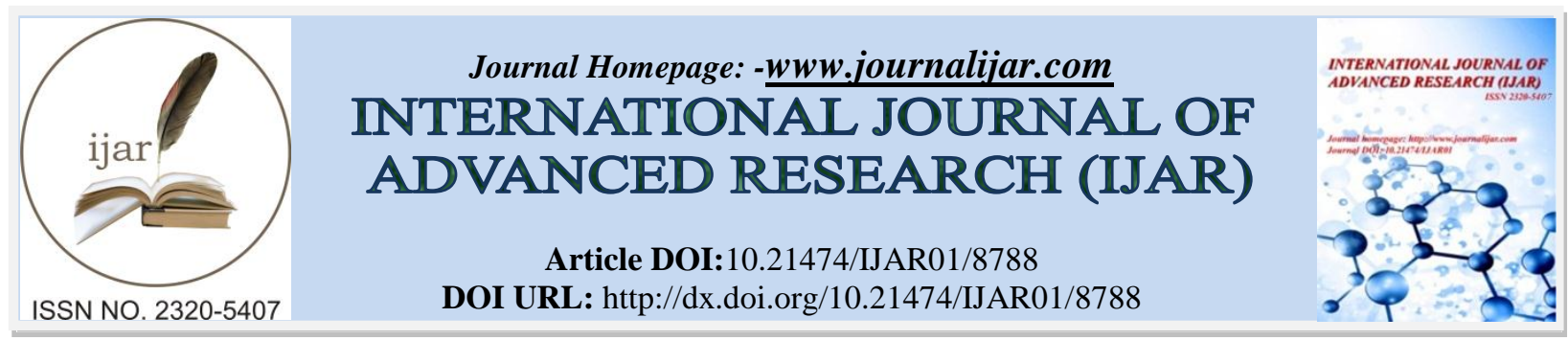

RESEARCH ARTICLE

\title{
GROWTH, SPECTROSCOPIC AND THERMAL CHARACTERIZATION OFTHIOSEMICARBAZONE OF M-NITROBENZALDEHYDE.
}

\section{Jeevarathinam ${ }^{1}$ and G. V. Pandian ${ }^{2}$.}

1. Department of Chemistry. Arignar Anna Govt. Arts \& Science College, Karaikal.

2. Department of Chemistry, T.B.M.L College, Porayar.

\section{Manuscript Info}

Manuscript History

Received: 02 February 2019

Final Accepted: 04 March 2019

Published: April 2019

Key words:-

Solution Growth, Slow Evaporation

Technique, Spectral Characterization,

Thermal Analysis, SHG Efficiency.

\begin{abstract}
Thiosemicarbazone of m-Nitrobenzaldehyde is an interesting organic crystal. It has been grown by slow evaporation solution growth technique (SESGT) using wood alcohol as solvent. The harvested crystals were purified by repeated recrystallization. The working groups of harvested crystals were examined by the Fourier Transform (FT-IR) spectral analysis. The UV-Visible Spectra are confirming the optical transparency. This is more helpful to use these crystals in electro optical applications. The harvested crystal Thiosemicarbazone of m-Nitrobenzaldehyde was characterized by proton nuclear magnetic resonance and of ${ }^{13} \mathrm{C}$ NMR spectra which show the molecular structure of the crystals. The TGA and DSC confirm the decay of the sample at $2100 \mathrm{o}$. It further confirms the grown crystals Thiosemicarbazone of m-Nitrobenzaldehyde is thermally stable up to $210^{\circ} \mathrm{C}$. The second harmonic generation efficiency of the powdered Thiosemicarbazone of m-Nitrobenzaldehyde and was tested using $\mathrm{Nd}$ : YAG laser and it is found to be 5.6 times higher than that of urea.
\end{abstract}

Copy Right, IJAR, 2019,. All rights reserved.

\section{Introduction:-}

Thiosemicarbazone of m-Nitrobenzaldehyde is an organic crystal plays a significant function in application in optical communication and optical computing devices. In recent year, an intense research work has been carried out to identify a special variety of thermally stable optical material. Organic compounds are often determined by very weak Vander walls and hydrogen bonds and possess a high degree of delocalization. Hence, they are optically more nonlinear than inorganic crystals. The growth methods depend on organic crystal size, hardness, physical body, and large nonlinear optical susceptibilities compared to the inorganic crystals. The slow evaporation solution growth Technique (SESGT) is an important technique because large size, stability, optical crystals are being created by this technique [1-6]. The harvested crystals were characterized by FT-IR, UV, 1H and 13C NMR, TGA-DSC, XRD, Micro hardness analysis, and SHG efficiency studied [7-12].

\section{Experimental}

An organic crystal of thiosemicarbazone of m-Nitrobenzaldehyde was prepared by adopting general procedure [1317]. To a hot solution of Thiosemicarbazone in methanol, a solution of $\mathrm{m}$-Nitrobenzaldehydein methanol was added drop wise during thirty minutes. The mixture was stirred and refluxed for 4 hours. It was filtered and the filtrate was concentrated to half the loudness. Later on a slow evaporation of the concentrate at room temperature, 
the Crystals were collected by filtration, rinsed with cold ethanol and dried in a void. These crystals are suitable for characterization studies.

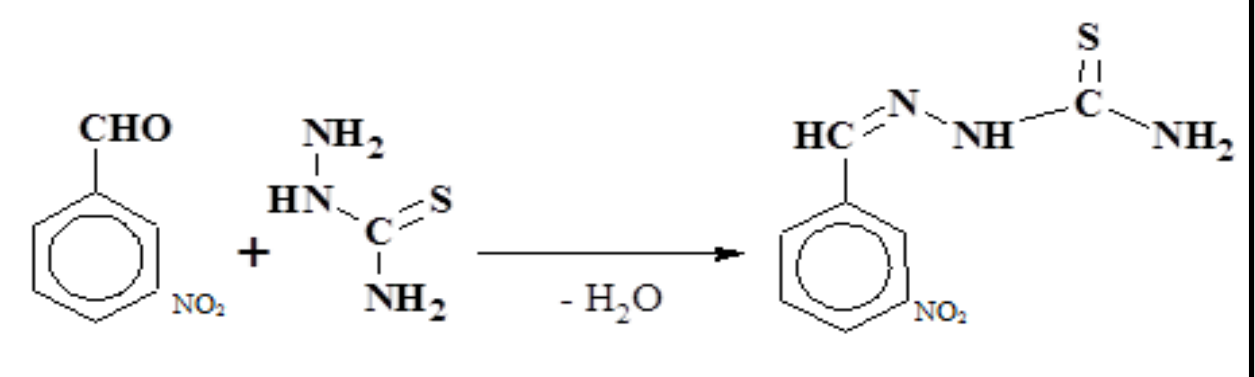

m-Nitrobenzaldehyde + Thiosemicarbazide $=$ Thiosemicarbazone of m-Nitrobenzaldehyde

\section{Result and Discussion:-}

\subsection{FT-IR Spectral analysis}

Working groups present in the sample were analyzed using AVTAR370 DTGS FT-IR spectrometer in the wave number range from $400-4000 \mathrm{~cm}-1$ using a $\mathrm{KBr}$ pellet technique. Fourier transform infrared (FT-IR) spectrum is an important book, which gives sufficient information about the construction of a compound. In this technique almost all working groups in a molecule absorb characteristic within a definite range of frequency. The concentration of infrared radiation makes the various alliances in a molecule to stretch and bend with respect to one another. The Fourier Infra-red spectrum of the grown crystal is indicated in the figure. 2. The observed and their corresponding group identification is made in Table 1 . The band obtained at $1600 \mathrm{~cm}-1$ is due to the establishment of the amine group between m-Nitrobenzaldehyde and thiosemicarbazide. Referable to the $\mathrm{C}=\mathrm{N}$ and $\mathrm{N}-\mathrm{N}$ is stretching, vibration the peaks observed at below $1540 \mathrm{~cm}-1$. The peak observed in $1159.23 \mathrm{~cm}^{-1}$ shows $\mathrm{C}=\mathrm{S}$ is stretching vibration. The peak observed at $1530 \mathrm{~cm}^{-1}$. Shows the presence of $-\mathrm{NO}_{2}$ group the peak corresponds to aromatic $\mathrm{C}-\mathrm{H}$ was observed in $1298 \mathrm{~cm}^{-1}$. At that point is, no peak observed at $2720 \mathrm{~cm}-1$ confirms the aldehyde functional group in mNitrobenzaldehyde of thiosemicarbazone. The spectral data obtained for the thiosemicarbazone of $\mathrm{m}$ Nitrobenzaldehyde are well in accordance with theoretical and literature values.

Figure1:-FT-IR Spectrum of thiosemicarbazone of m-Nitrobenzaldehyde

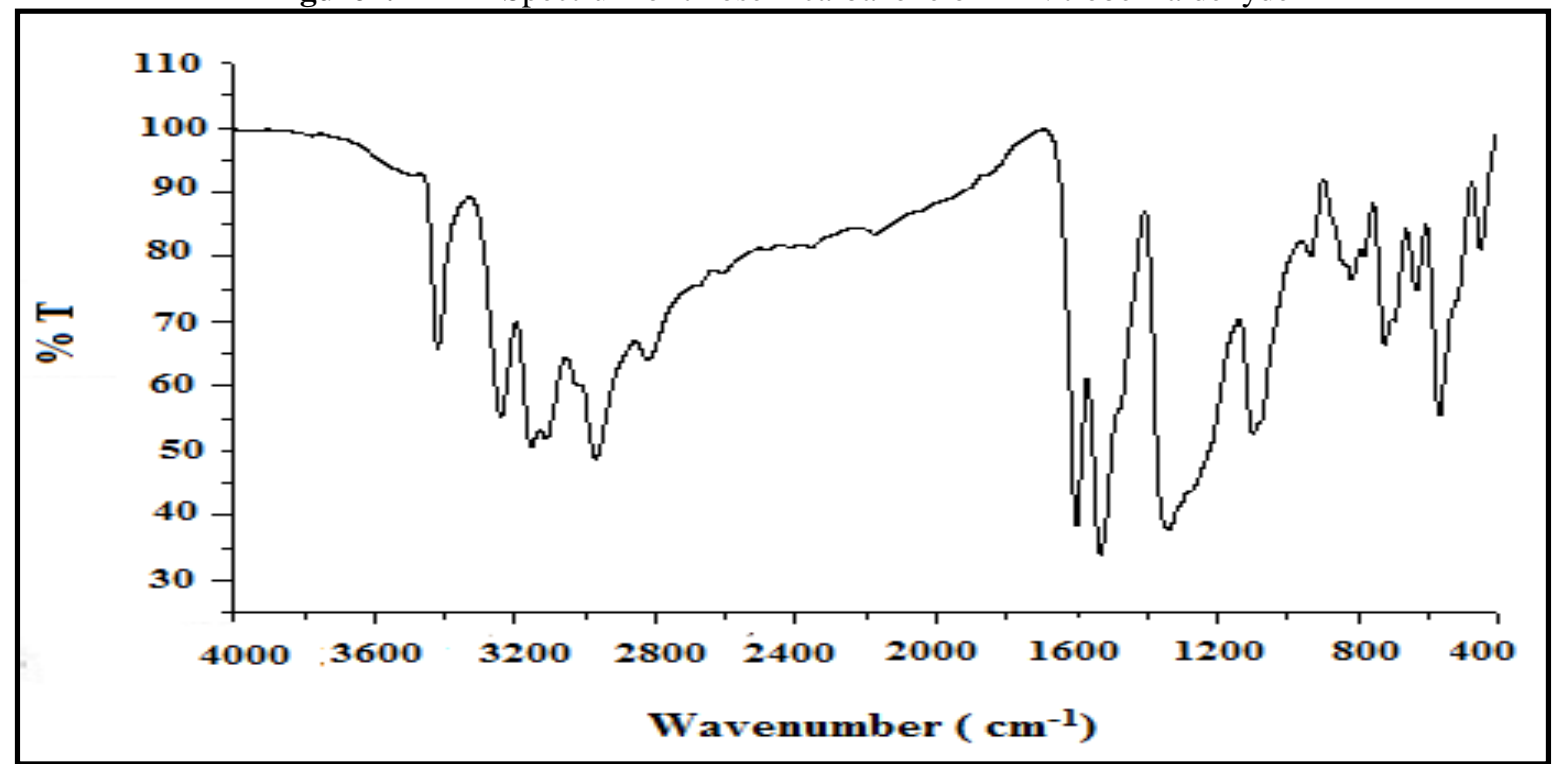

Table1:-FT-IR Spectral data of thiosemicarbazone of m-Nitrobenzaldehyde
S. No
Frequency $\mathbf{~ c m}^{-1}$
Group designation 


\begin{tabular}{|l|l|l|}
\hline 1 & 3419 & N-H amine group \\
\hline 2 & 3252 & N-H Stretching \\
\hline 3 & 1298 & Aromatic C-H \\
\hline 4 & 1540 & N-N Stretching \\
\hline 5 & 1530 & $\mathrm{C}-\mathrm{NO}_{2}$ group \\
\hline 6 & 1600 & $\mathrm{C}=\mathrm{N}$ imine group \\
\hline 7 & 1159 & $\mathrm{C}=\mathrm{S}$ Stretching \\
\hline 8 & 1107 & $\mathrm{NH}_{2}$ rocking \\
\hline
\end{tabular}

\subsection{UV- Visible Spectral studies}

Ultraviolet-Visible Spectroscopy is also known as electronic spectroscopy. UV- $\quad$ (200-400nm) and Visible (400$800 \mathrm{~nm}$ ) absorption spectroscopy is the measurement of the attenuation of a beam of light after if passes through a sample or after reflection from a sample surface. This is characteristic of a particular compound, Qualitative and Quantitative estimation of the compound are possible by this non destructive technique. The purity of chemically synthesized m-NBTSC compound was carried by measuring the UV-Visible spectra between 200-900 nanometer. UV-Visible spectroscopy analysis has been performed using a Perkin-Elmer Lambda-35 spectrophotometer operated at a settlement of $1 \mathrm{NM}$ as a function of response time. The recorded UV-Visible spectrum proves the highly transparent nature of the material between $500-900 \mathrm{~nm}$.

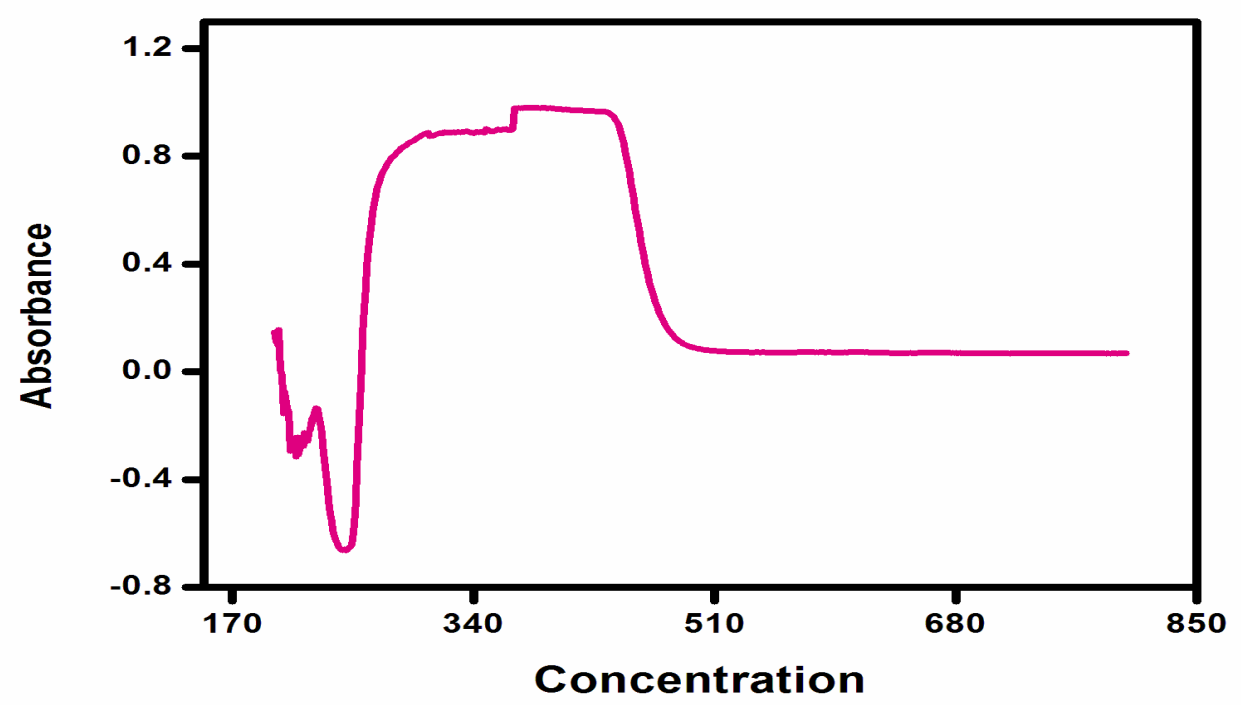

Figure 2:-UV-Visible Spectrum of Thiosemicarbazone of m-Nitrobenzaldehyde

\subsection{Raman Spectral analysis}

Raman is a spectroscopic technique used to observe vibrational, rotational, and other low-frequency modes in a system. Raman spectroscopic analysis is commonly employed in chemistry to provide a structural fingerprint by which particles can be distinguished. The Raman spectrum of the thiosemicarbazone of m-Nitrobenzaldehyde crystal was recorded from 200 to $800 \mathrm{~cm} 1$ at room temperature 


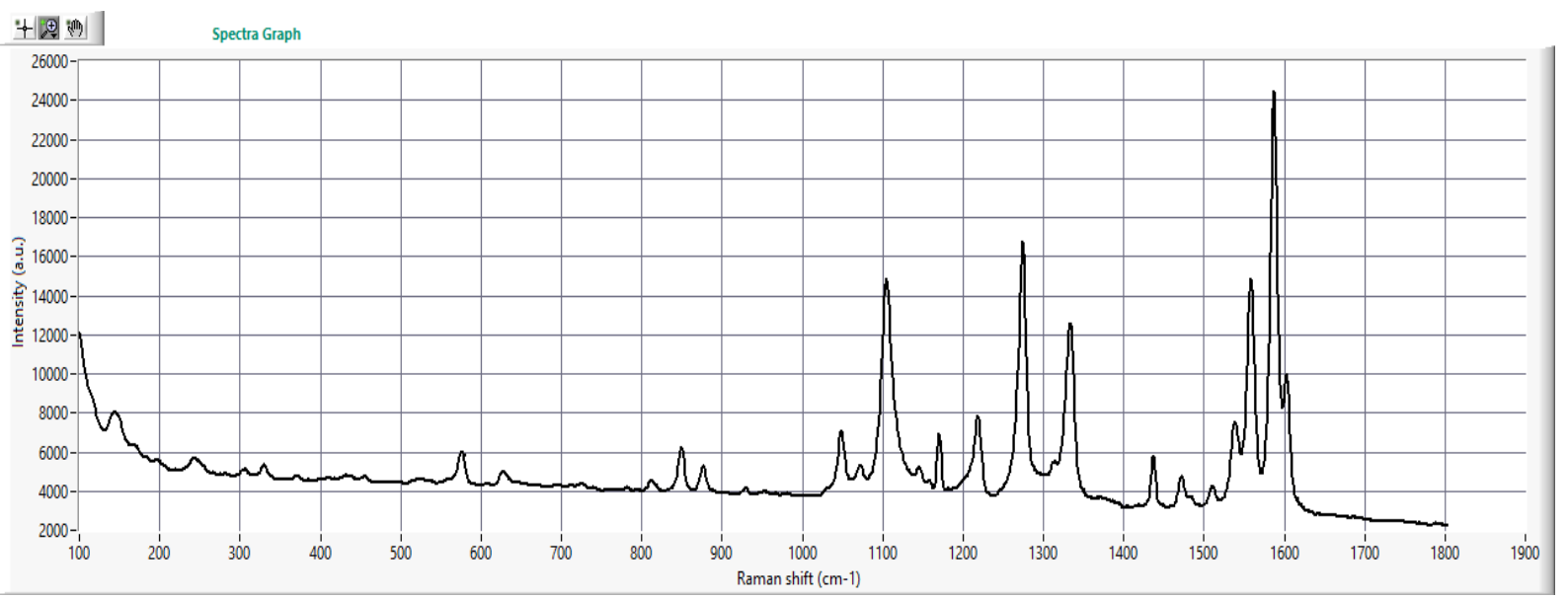

Figure3:-Raman of Thiosemicarbazone of m-Nitrobenzaldehyde

\subsection{NMR Spectral analysis}

\section{H NMR Spectral Analysis}

The Nuclear Magnetic Resonance Spectral analysis is useful in the determination of the molecular structure based on the chemical environment of the magnetic nuclei such as $1 \mathrm{H}, 13 \mathrm{C}, 31 \mathrm{P}$ etc., even at low concentrations. The $1 \mathrm{H}$ NMR spectral analysis was run out of them-Nitrobenzaldehyde of thiosemicarbazone in BRUKER 300 NMR spectrometer using DMSO as solvent. The 1H NMR spectra of thiosemicarbazone of m-Nitrobenzaldehyde is shown in image 4. A signal observed at $\delta=8.24 \mathrm{ppm}$ is corresponds to the $\mathrm{NH}_{2}$ protons of hydroxide group. A singlet at $\delta=8.055 \mathrm{ppm}$ confirm the NH proton. The multiplied observed between $\delta=7.370$ and $7.801 \mathrm{ppm}$ confirms the presence of aromatic protons. The presence of peak at $\delta=4.216 \mathrm{ppm}$ indicates the $\mathrm{HC}=\mathrm{N}$ protons. The signal at $\delta=3.451 \mathrm{ppm}$ shows the HOD signals of the solvent. The peaks at $\delta=1.276$ confirms the $\mathrm{CH}$ protons. The signal at $\delta=2.501$ indicates the residual protons present in DMSO d6 solvent [150]. The spectral data obtained for the $\mathrm{m}-$ Nitrobenzaldehydes of thiosemicarbazone are well in accordance with theoretical and literature values.

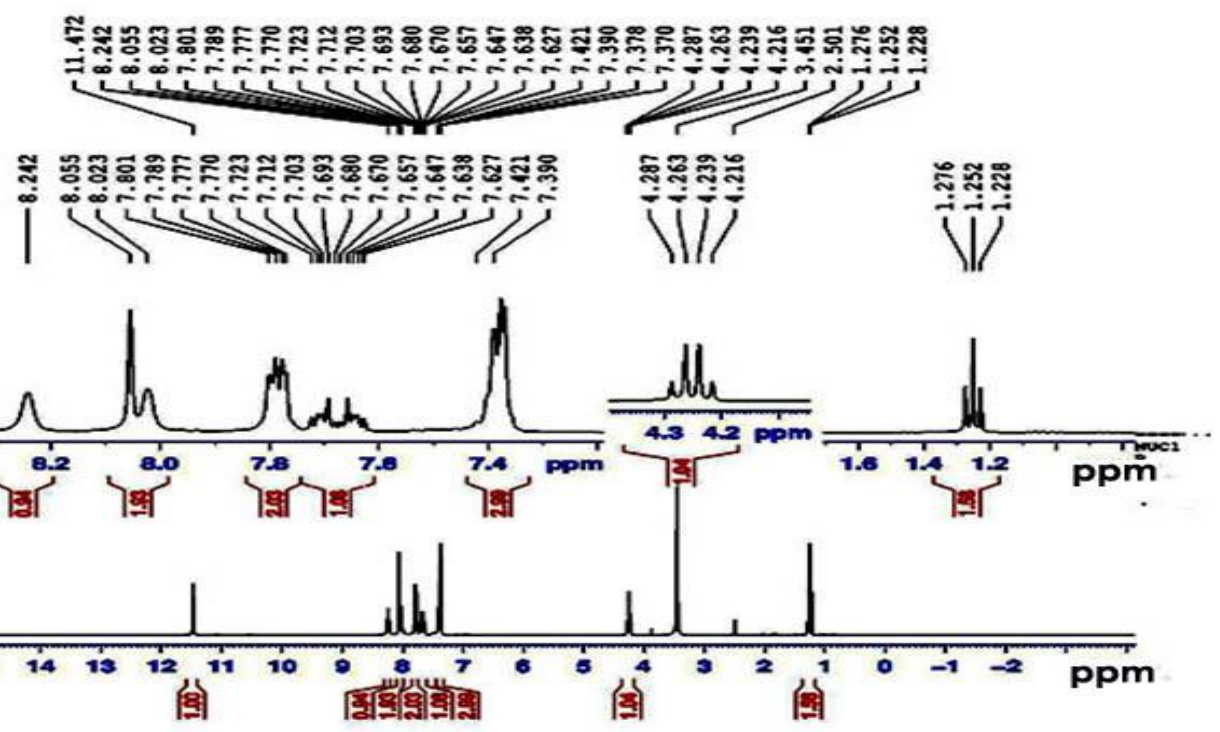

Figure 4:- ${ }^{1} \mathrm{H}-\mathrm{NMR}$ Spectrum of Thiosemicarbazone of m-Nitrobenzaldehyde

\section{${ }^{13}$ C-NMR Spectral analysis}

The ${ }^{13} \mathrm{C}$ NMR spectra of m-Nitrobenzaldehyde of thiosemicarbazone was recorded using BRUKER 300 NMR spectrometer using DMSO as solvent. The13C NMR Spectrum of $\mathrm{m}$-Nitrobenzaldehyde of thiosemicarbazone is shown in image 5 . The amine group is mapped by the signal at $\delta=167.01 \mathrm{ppm}$ The multiple peak at $\delta=127.36$ - 
$134.74 \mathrm{ppm}$ represents the bearing of the benzine ring. The bearing of a peak at $\delta=13.94 \mathrm{ppm}$ confirms the substituted aromatic compound. The presence of residual protons present in DMSO d6 observed at $\delta=40 \mathrm{ppm}$. The absence of peak at 25 and $17 \mathrm{ppm}$ confirms the absence of methylene aliphatic group. The correlation of the signals observed in $1 \mathrm{H}$ and $13 \mathrm{C}$ NMR spectra with the functional group is recorded in Table 3. This correlation is well in accordance with the theoretical and standard values.

Figure 5:- ${ }^{13} \mathrm{C}$-NMR Spectrum of m-Nitrobenzaldehyde of thiosemicarbazone

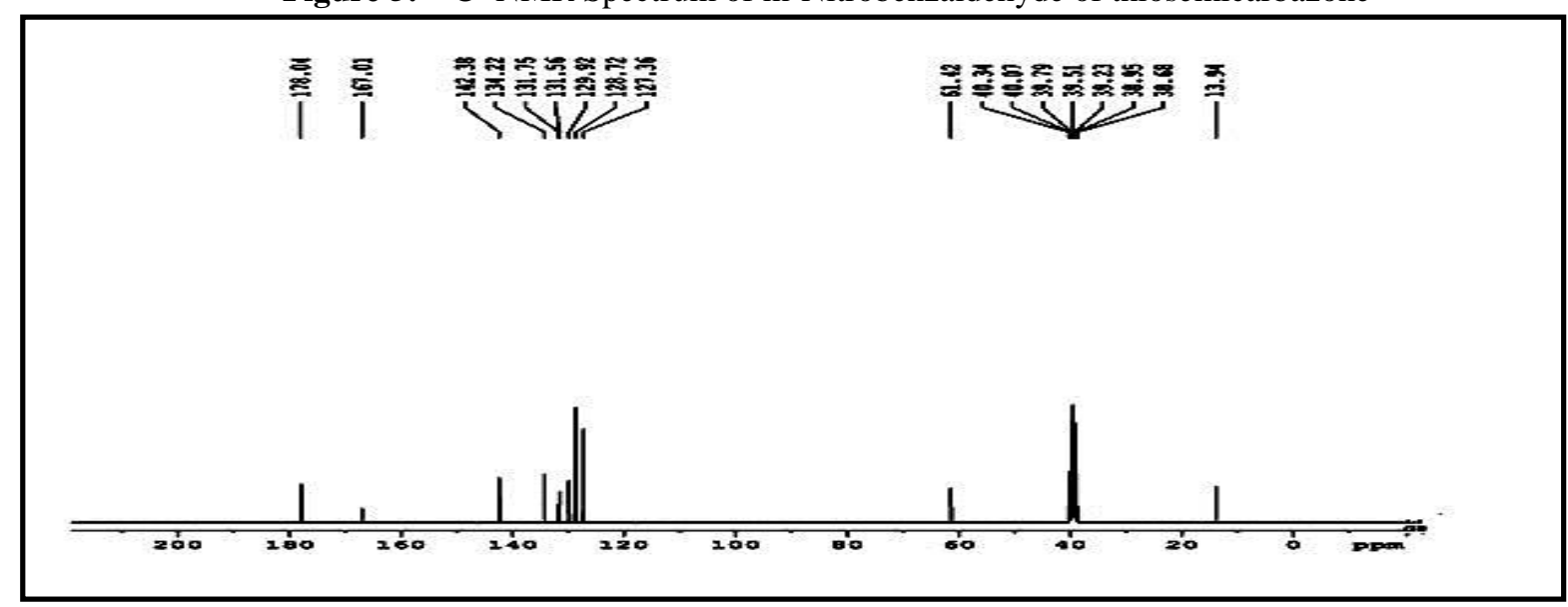

Table 3:-NMR Spectral data of m-Nitrobenzaldehyde of thiosemicarbazone

\begin{tabular}{|c|c|l|}
\hline Spectrum & Signal at $\boldsymbol{\delta} \mathbf{~ p p m}$ & \multicolumn{1}{c|}{ Group identification } \\
\hline \multirow{4}{*}{$\mathrm{H}$} & 8.242 & $\mathrm{NH}_{2}$ proton of hydrazide \\
\cline { 2 - 3 } & 8.055 & NH-proton \\
\cline { 2 - 3 } & $7.370-7.801$ & Aromatic protons \\
\cline { 2 - 3 } & 4.216 & HC=N protons \\
\cline { 2 - 3 } & 1.276 & $\mathrm{CH}$ protons \\
\hline \multirow{4}{*}{${ }^{13} \mathrm{C}$} & 167.01 & Imine group \\
\cline { 2 - 3 } & 142.38 & $\mathrm{C}=$ S group \\
\cline { 2 - 3 } & $127.36-134.74$ & Benzene ring \\
\cline { 2 - 3 } & 13.94 & Substituted aromatic compound \\
\hline
\end{tabular}

\subsection{Nonlinear optical studies}

At Kurt's and Perry second harmonic generation (SHG) test [32] was performed to determine the NLO efficiency of Thiosemicarbazone of m-Nitrobenzaldehyde crystal. The grown crystal was powdered with a uniform particle size and bundled in a micro capillary of uniform bore and was illuminated using spectra physics quanta ray DHS2.Nd:YAG laser is applied to test second harmonic generation (SHG) of growing crystals, The SHG efficiency obtained for Thiosemicarbazone of m-Nitrobenzaldehyde is about 5.6 times that of Urea.

\section{Conclusion:-}

Thiosemicarbazone of m-Nitrobenzaldehyde was prepared by using a methanol solution by assuming a standard routine. The crystal was grown by slow evaporation solution growth technique (SESGT). The presence of Nitro group and the nature of the protons were identified by FT-IR and ${ }^{13} \mathrm{C} ;{ }^{1} \mathrm{H}$ NMR Spectral analysis. The UV-Visible spectrum reveals that the grown crystal is transparent in the wavelength area. Thermal stability of the crystal was confirmed by TGA/DSC studies. The NLO test confirms the SHG efficiency of Thiosemicarbazone of mNitrobenzaldehyde

\section{Acknowledgement:-}

One of the authors (GVP) thank the University Grant Commission, New Delhi for the award of UGC: minor project [File No. 4- 1/2008 (BSR)]. The authors thank the management and principal of T. B. M. L. College for their bread and butter. The authors are thankful to the Dr. Brindha Department of Center for Advanced Research in Indian System of Medicine (CARISM). 


\section{Reference:-}

1. Manivannan S, Danuskodi S. Growth and characterization of a new organic nonlinear crystal: Semicarbazone of N-dimethylaminebenzaldehydeJCrystal growth 257 (2003) 305-308.

2. Vasudevan G, Anbusrinivasan P, Madhurambal G, Mojumdar SC .Thermal analysis effect of dopantsSpectral characterization and growth aspect of KAP crystals.J Therm Anal Calorim 2009 (96) 99-102. Anbusrinivasan P, Pandian G.V, Determination of Nucleation Temperature, metestablezone with spectral analysis of sulphanilic acid grown from Ethanol-Water as growth medium; Ultra chemistry Vol 8 (1), 83-90 (2012).

3. RamachandraRaja C, Ramamoorthi K,Manimekalai.R, Growth and spectroscopic characterization of ethylene diamine tetra acetic acid (EDTA) doped Zinc sulphatehepta hydrate-A semi organic NLO material, Spectrochimica Acta Part a 99(2012)23-26.

4. Madhurambal G ,Ramasamy P, Anbusrinivasan P, Vasudevan G, Kavitha S, Majumdar SC, Growth and characterization studies of 2- bromo-4"-Chloro-acetophenone (BCAP) crystals.J Therm Anal calorim 2008; 94:59-62.

5. Anbusrinivasan P, Pandian G.V, Determination of Nucleation Temperature, metestablezone with spectral analysis of sulphanilic acid grown from Ethanol-Water as growth medium;Ultra chemistry vol 8(1),8390(2012).

6. Ramalingam S, Anbusrinivasan P, Periandy S: FT-IR and FT-Raman Spectral Investigation, Computed IRIntensity and Raman activity analysis and frequency estimation analysis on 4-chloro-2-bromoacetophenone was - HF and DFT calculations; Spectrochimica Acta part A 2011 (78) 826-834.

7. Yuan-Zhang, Yonggangwang, Yunxiache, Jiminezheng Growth and properties of two new organic nonlinear optical crystals; Hydroxyethylammonium-1-tartrate monohydrate and Hydroxyethylammonium-o-tartrate monohydrate. J crystal growth 299 (2007) 120-124.

8. Rajasekaran M, Anbusrinivasan P, Mojumdar SC, Growth, Spectral and thermal characterization of 8hydroxyquinoline, J. Therm calorim (2010) 100:827-830.

9. Sankaranarayanan K, Ramasamy P, Unidirectional crystallization of large diameter benzophenone single crystal from solution at ambient temperature. J crystal growth 292 (2006)445-448.

10. Arulchakkaravarthi A, Jayavel P, santhanaragavan P, Ramasamy P .Growth of organic molecular single crystal trans-stilbene by selective self-seeding from vertical Bridgman technique .JCrystal Growth 2002( 234) 159163.

11. Subashini A, Bhavannarayana G, Ramamurthi K, Investigation on growth and crystalline perfection of an organic Schiff base material: 4-chloro-4" bromobenzylidene aniline, Spectrochimica Acta part A 96 (2012)716722.

12. Srinivasan P, Gunasekaran M, Ganagasekaran T, Gobalakrishnan R, Ramasamy P.2, 4, 6-trinitrophenol (TNP); an organic material for nonlinear optical applications. J Crystal Growth 2006 (289) 639-646.

13. WiliredoHermandeza, Juanpaz, AbrahamVaisberg, EvgeniaSpodine, Rainer Richter and Lothar Beyer, Synthesis, Characterization and in Vitro Cytotoxic Activities of Benzaldehyde Thiosemicarbazone Derivatives and their Palladium (II) complexes against various Human Tumor cell lines, Bioinorgchem Appl-v 2008, 2008, PMC2615113.

14. Santhakumari R, Ramamurthy K Structural, Thermal and optical characterization of an organic NLO materialBenz aldehyde Thiosemicarbazone monohydrate single crystals, Spectro chemical Acta part A: 78 (2011) 653659.

15. Formation characterization and structural studies of novel thiosemicarbazone Palladium (II) complexes. Vila JM, Pereira Mat, Ortigueira JM, etal.J. Chemicalsocity, Dalton Transactions 1999 (23) 4193-4201.

16. Sethuraman K, Ramesh Babu K, Vijayan N, Gobalakrishnan R, Ramasamy P, Synthesis, growth of organic nonlinear optical crystal; Semicarbazone of 2-amino -5-chloro -benzophenone (S2A5CB) and its characterization. Crystal growth 2006 (290) 539-543.

17. Janarthanam S. Rajan Y.C, Umarani P.R, Selvakumar S, Pandi S Synthesis and characterization of Semicarbazone p-Hydroxy-3-Methoxy acetophenone (SPH3MA) Single crystal.Physica.B-condenced matter 2011( 406) 135-138.

18. Mojumdar SC. Thermoanalytical and IR spectroscopy investigation of $\mathrm{Mg}(\mathrm{II})$ complexes with hetrocyclic ligands .J Therm Anal Calorim.2001 (64) 629-36.

19. Madhurambal G, Mojumdar SC, Hariharan S, Ramasamy P, TG, DTC, FT-IR and Raman spectral analysis of ZNIMg, Ammoniumsulphate mixed crystals; J Therm Anal Calorim 2004 (78) 125-33.

20. Preema. C Thomas, Langabhushankumar, A. Anuradha. S. Aruna, Ginsonp. Joseph, P.Sagayaraj, Growth and characterization of nonlinear optical single crystals of L-argininediiodate, J.crystal growth 2006(290) 560-564. 
21. Sweta M, TamusreeK, Growth and characterization of nonlinear optical crystal Zinc tris (thiourea) sulphate in presence of L-arginate. Optical mat 2007; 30: 508-512.

22. Jayalakshmi D, Kumar J. Growth and characterization of bisthiourea Zinc acetate, Cryst Res Technol, 2006:41, $37-40$.

23. Narayanamoolaya B. Dharmaprakash S.M. Synthesis, growth and characterization of nonlinear optical crystal L-tyrosine hydro bromide. J Crystal growth 290 (2006) 498-503..

24. Balakrishnan, T, Ramamurthi K, Crystal growth, Structural, optical, mechanical and thermal properties of a new nonlinear optical single crystal L-Ornithine monohydrochloride, Spectrochimica Acta part A 72 (2009) 269273.

25. Mojumdar SC, Miklovic J, Krutosikova A, Valigura D, Stewart J M. Furopyridine-Ni (II) complexes-Synthesis, Thermal and spectral characterization. J Therm Anal Calorim. 2005(81) 211-215.

26. William Kemp, Organic spectroscopy-Third edition-1991.

27. Ramesh Babu R, Ramesh R. Gopalakrishnan R, Ramamurthi K, Bhagavannarayana G, Growth, Structural, optical, mechanical and optical properties of pure and metal ions doped sulphamic acid single crystals. Spectrochimica Acta part A 76 (2010) 470-475.

28. Sangeetha K, Ramesh Babu R, Bhagavannarayana G, Ramamurthi K, Structural, Spectral, optical and dielectric properties of copper and Glycine doped LAHCL single crystals, Spectrochimica Acta part A 79(2011)10171023.

29. Dos Santos M.H, Nagem T.J, Braz-Filho R, ILuta I.S and Speziali N.L Complete assignment of the ${ }^{1} \mathrm{H}$ and ${ }^{13} \mathrm{C}$ NMR spectra of the tetraaisoprenylatedbenzophenone15-epiclusianone Magn. Reson.Chem. (2001); 39:155158.

30. Sudha S Belgur, Ravindra R. Kamble and Sheena shashikanth, A convinent preparation of novel benzophenonederivaties J,Serb, Chem,Chem;(2008) 73(3)261-269.

31. Myoung-chongsong, FikruNigussie, Hye-Joung Yang and Nam-In Back, A New benzophenone from Linderafruticosa, Bull,Koream Chem, Soc,(2007) 28(7) 1209.

32. Kurtz S.K, Perry T.T, J.Appl.Phys.39 (1968) 3798-3813.

33. Porob RA, Khan SZ, Mojumdar SC, Verankar VMS ,Synthesis, TG, SDC and infra-red spectral study of Nimn2(C2H4O4)36N2H4-A precursor for NiMn2O4 nanoparticles; J Therm Anal Calorim 2006 (86) 605-612.

34. Meera. K, Muralitharan R, Tripathi AK, Dhanasekaran R. Growth of Thiourea doped TGS crystals and their characterization, J. Cryst Growth 2004-260:414-421.

35. Mojumdar SC. Thermoanalytical and IR spectroscopy investigation of $\mathrm{Mg}$ (II) complexes with hetrocyclic ligands .J Therm Anal Calorim. 2001 (64) 629-636.XRD

36. Sawant SY, Verenkar VMS, Mojumdar SC. Preparation, Thermal, XRD, chemical and FT-IR spectral analysis of NiMn2O4 nanoparticles and respective precursor; J Therm Anal Calorim 2007 (90) 669-672.

37. Vila JM, Pereira Mat, Ortigueira JM, et al, Formation characterization and structural studies of novel thiosemicarbazone Palladium (II) complexes. J. Chemicalsocity, Dalton Transitions 1999 (23) 4,193-4201.

38. Uma Devi T, Lawrence N, RameshBabu R, Ramamurthi K, Growth and characterization of Glycine picrate single crystal;Spectrochimical Acta part A 71 (2008) 340-343.

39. Leela S, Hema R, Helenstoeckli Evans, Ramamurthi K, Bhagavannarayana. G, Design, Synthesis, growth and characterization of 4-Methoxy-4" dimethylamino-benzylidine aniline (MDMABA): A novel third order nonlinear optical material, Spectrochimica Acta part A 77 (2010)927-932.

40. Ravindrachary V, Bajantri R F, Richard Goncalves, Growth and characterization of an organic NLO Crystals 1-(4-methyl phenyl ) -3-(4- methoxy phenyl) -2-propene -3-one.J. Crystal growth, 2004 (267) 129-133.

41. Renoylds G.F, in D. Fox. A. Weiss Berger M.M. Labes (Eds) Physics and Chemistry of the organic Solid States Vol.1.Wileley Inter science new York1963 pp. 223-286. 